\title{
Aprendizagem matemática através da elaboração de problemas em uma escola comunitária rural
}

\author{
Mathematics learning through elaboration of problems in a rural community \\ school
}

\author{
Cidimar Andreatta
}

Norma Suely Gomes Allevato

\begin{abstract}
Resumo: Neste artigo, apresentamos resultado de uma pesquisa de doutorado realizada com estudantes do $5^{\circ}$ ano do Ensino Fundamental de uma Escola Municipal Comunitária Rural, cujo objetivo foi investigar como problemas elaborados pelos estudantes podem contribuir para suas aprendizagens. Os dados foram construídos por meio da observação participante e da análise do enredo textual dos problemas elaborados pelos estudantes em um contexto de aprendizagem que levou em consideração conteúdos desenvolvidos por eles em etapas anteriores da pesquisa. Com abordagem qualitativa, a investigação configura-se como pesquisa-ação, em que os dados foram submetidos à análise textual discursiva a partir dos registros da elaboração dos problemas e das observações. Os resultados mostram que os problemas elaborados pelos estudantes estiveram relacionados, em sua maior parte, às operações fundamentais da Matemática, especialmente a
\end{abstract} adição e multiplicação como potencial para desenvolver aspectos da criatividade e da criticidade dos estudantes.

Palavras-chave: Educação Matemática. Elaboração de Problemas. Aprendizagem discente.

Abstract: In the article, we present results of a research carried out with 5th year students of elementary school at a Municipal Rural Community School, whose objective was to investigate how problems developed by students can contribute to student learning. In this text, we present data constructed through participant observation and analysis of the textual plot of problems developed by students in a learning context that took into account content addressed in the generating problems developed by students in previous stages of the research. With a qualitative approach, research is configured as action research, and the data were subjected to textual discursive analysis from the records of the elaboration of problems and observations. The

Cidimar Andreatta Doutorando em Ensino de Ciências e Matemática pela Universidade Cruzeiro do Sul. Professor das Faculdades Integradas de Linhares (FACELI). Espírito Santo, Brasil. iD orcid.org/0000-0001-5807-8896 $\bowtie$ cidimarcol@gmail.com Norma Suely Gomes Allevato Doutora em Educação Matemática. Professora do Programa de Pós-Graduação em Ensino de Ciências e Matemática da Universidade Cruzeiro do Sul. São Paulo, Brasil.

iD orcid.org/0000-0001-6892-606X

$\bowtie$ normallev@gmail.com

Recebido em 27/02/2020 Aceito em 24/03/2020 Publicado em 11/04/2020 results demonstrate that most of the problems elaborated by the students were related to the fundamental operations of mathematics, especially the addition and multiplication, as well as the potential to develop aspects of students' creativity and criticality.

Keywords: Mathematics Education. Elaboration of Problems. Student Learning.

\section{Introdução}

O foco da pesquisa aqui descrita será a análise de como ocorre a aprendizagem matemática através da elaboração de problemas por estudantes de uma turma do $5^{\circ}$ ano do 
Ensino Fundamental de uma Escola Municipal Comunitária Rural. Localizada na região noroeste do estado do Espírito Santo, a escola dista aproximadamente 160 quilômetros da cidade de Vitória, capital do Estado.

No contexto da competência e da criatividade para elaborar problemas e realizar problematizações é que propomos o desenvolvimento desta pesquisa ${ }^{1}$. A elaboração de problemas também se configura como recurso e oportunidade de aprendizagem matemática, tendo em vista que ela também impulsiona o trabalho com a resolução de problemas e pode ocorrer a qualquer momento do processo de sua resolução e exploração.

O contexto de aprendizagem que se constituiu para a pesquisa descrita neste artigo ocorreu em etapas anteriores da investigação, por meio de um trabalho de resolução de problemas geradores realizado pelos estudantes, com a mediação da professora regente e do pesquisador, em que a Metodologia de Ensino-Aprendizagem-Avaliação de Matemática através da Resolução de Problemas (RP) foi efetivada. Esse trabalho ocorreu no período de agosto a outubro de 2018. Portanto, a elaboração de problemas se deu não imediatamente após a resolução de cada problema gerador, mas depois do trabalho com todos os problemas geradores, no dia 16 de outubro de 2018, como parte integrante dessa metodologia.

Em um ambiente de liberdade e criatividade pela escolha do contexto e das incógnitas do problema, foram retomadas com os estudantes as etapas já mencionadas da resolução dos problemas geradores, no intuito de apresentar possibilidades e sugestões para a décima etapa, referente à proposição de novos problemas, que, neste caso, consistiu na elaboração de problemas. A especificação desses problemas geradores e seus conteúdos estão detalhados na seção de metodologia.

Apresentando o percurso da pesquisa, estruturamos este texto em seis seções, incluindo esta introdução e as referências. Na introdução pontuamos o contexto e o objetivo da pesquisa. Na segunda seção desenvolvemos uma discussão teórica sobre a perspectiva da elaboração de problemas na aprendizagem matemática. Em seguida, na terceira seção, expomos os procedimentos metodológicos alinhados à quarta seção, dedicada à descrição e à análise dos problemas elaborados pelos estudantes. Por fim, apresentamos as considerações finais e as referências.

\footnotetext{
${ }^{1}$ A pesquisa foi aprovada pelo Comitê de Ética via plataforma Brasil pelo parecer número 2.439.347, em 14 de dezembro de 2017.
} 


\section{Aprendizagem matemática na perspectiva da Elaboração de Problemas}

Antes de explorarmos a perspectiva da Elaboração de Problemas, é importante considerar aspectos relacionados ao conceito de problema. De acordo com o Dicionário Houaiss da Língua Portuguesa, a palavra "problema" é de origem latina, com o mesmo significado adaptado do grego. Significa "obstáculo, o que é proposto, tarefa, assunto controverso"; e, ainda, "lançar, dar o sinal, impedir, começar uma luta" e outros tantos (HOUAISS, VILLAR e FRANCO, 2001, p. 226).

Para muitas pessoas, problema é visto como algo negativo, que escapa da rotina em situações do cotidiano. No espaço escolar, na perspectiva do aluno, é uma situação complexa vinculada ao currículo, originada dos conteúdos que são ensinados. Problemas são, em certas concepções, usados como instrumentos para treinamentos de técnicas e métodos que se apresentam sem contextualização social, política ou cultural com o aluno.

Para Hiebert et al. apud Van de Walle (2009, p. 57), um problema pode ser "qualquer tarefa ou atividade na qual os estudantes não tenham nenhum método ou regra já receitados ou memorizados e nem haja uma percepção por parte dos estudantes de que haja um método 'correto' específico de solução". Nessa perspectiva, Van de Walle (2009) destaca que um problema voltado para a aprendizagem matemática possui algumas características: (i) ele deve começar onde os estudantes estão, ou seja, deve ser desafiador e interessante e fazer sentido para 0 estudante; (ii) o aspecto problemático ou envolvente do problema deve estar relacionado à Matemática que os alunos vão aprender, para que o foco principal seja a compreensão das ideias matemáticas, e não o contexto dos problemas e/ou atividades não matemáticas, como cortar, colorir gráficos etc.; (iii) a aprendizagem matemática nele envolvida deve requerer justificativas e explicações para as respostas e os métodos, pois os estudantes precisam compreender que é sua a responsabilidade para determinar e justificar se as respostas estão corretas.

Indo ao encontro das considerações de Van de Walle (2009), entendemos que a Matemática pode ser ensinada através da Resolução de Problemas. As situações e/ou problemas são o veículo para a aprendizagem de conteúdos e conceitos matemáticos, e a aprendizagem resulta do processo de resolução do problema.

Ampliando essa perspectiva do processo de Resolução de Problemas, propomos uma discussão acerca da elaboração de problemas incluída nesse processo. Andrade (2017) destaca que podemos ir além do processo de resolução do problema em si e defende tal processo como Exploração-Resolução-Proposição de Problemas (ERP), numa dimensão mais ampla, no sentido 
de pensar "a ideia de problema como alguma coisa que não compreende apenas a resolução do problema ou situação-problema, mas a sua exploração em toda a sua multicontextualidade" (p. $365)$.

Nesse sentido, entendemos que a elaboração de problemas por parte dos estudantes ocorreu em um contexto de aprendizagem maior iniciado anteriormente. $\mathrm{O}$ desenvolvimento de aulas fundamentadas na resolução dos problemas geradores foi importante para esse entendimento do processo de resolução de problemas em um contexto mais amplo, na presente pesquisa.

Quando nos referimos a um contexto mais amplo de aprendizagem, estamos entendendo o processo de Resolução de Problemas não somente como a resolução para a obtenção da resposta do problema em si, mas como todo o processo de resolução, envolvendo a autonomia do estudante, a criatividade, a reflexão, o diálogo, a interpretação, a argumentação, a criação de diferentes estratégias, a habilidade para resolver diferentes problemas, assim como a competência para propor problemas e realizar problematizações.

Desse modo, neste artigo, utilizamos o termo "Elaboração de Problemas" para designar a construção dos textos dos problemas pelos estudantes integrantes da pesquisa. Esse processo configurou-se após as nove etapas da metodologia de Ensino-Aprendizagem-Avaliação de Matemática através da RP2 (ALLEVATO e ONUCHIC, 2014), compondo, assim, a décima e última etapa da metodologia.

Sendo assim, concordamos com Cruz e Ramirez (2006) apud Gontijo et al. (2019), ao afirmarem que a Elaboração de Problemas é uma atividade humana que pode ser realizada por meio de três etapas essenciais: "a formulação (uma pergunta inicial fornece os elementos que provocarão o sujeito a formular uma questão), a resolução (o sujeito busca solucionar a questão formulada testando sua validade) e o aprimoramento (são feitas alterações com 0 intuito de aprimorar o problema elaborado)" (p. 66).

Corroborando essas etapas, percebemos a importância de o professor fornecer elementos, contextos e condições para que os estudantes desenvolvam a capacidade de elaborar

\footnotetext{
2 As professoras e pesquisadoras brasileiras, Norma Suely Gomes Allevato e Lourdes de la Rosa Onuchic, organizaram um roteiro sugerindo etapas que podem auxiliar os professores que desejam ensinar através da Resolução de Problemas. A terceira edição desse roteiro é constituída de dez etapas: preparação do problema; leitura individual; leitura em conjunto; resolução do problema; (professor) observar e incentivar; registro das resoluções na lousa; plenária; busca do consenso; formalização do conteúdo; e proposição de novos problemas.
} 
problemas, de modo a discutir a realidade, levando em consideração aspectos do conhecimento trabalhados na escola. As atividades com a elaboração de problemas podem promover 0 envolvimento e a aprendizagem dos alunos com a Matemática, além de permitir que enfrentem problemas com diversos métodos e soluções. Silver e Cai (2005) apud Gontijo et al. (2019) afirmam que "as tarefas de formulação de problemas estão entre as mais utilizadas quando 0 objetivo é identificar indivíduos criativos" (p. 67).

A aprendizagem matemática pode ocorrer também em um ambiente de elaboração e/ou formulação de problemas que não esteja diretamente relacionado à aplicação de algoritmos, teoremas e resoluções-padrão, de forma que a criatividade e a liberdade de utilizar conhecimentos prévios seja valorizada de diferentes formas (GONTIJO, 2006).

Também Bonotto (2012) destaca que a experiência de descobrir e criar seus próprios problemas deve fazer parte da educação de todos os estudantes, considerando que essa experiência tem potencial para identificar e estimular o pensamento criativo em Matemática. A pesquisa da autora, realizada com estudantes do $5^{\circ}$ ano do Ensino Fundamental, mostrou a possibilidade e a viabilidade do trabalho com a elaboração de problemas, podendo fomentar nos estudantes o pensamento flexível e criativo, que os levam a propor ideias e dados adicionais, diferentes do contexto de aprendizagem a que estão habituados.

Nesse mesmo sentido, Dante (2011) destaca que os estudantes, ao terem em sala de aula a oportunidade de criar e inventar os próprios problemas, podem ser motivados a lê-los, compreendê-los e resolvê-los, porque os problemas são "deles".

É importante salientar que a Elaboração de Problemas pode tornar-se uma possibilidade no ensino de conteúdos e conceitos matemáticos, tendo em vista que o estudante é desafiado a problematizar situações do cotidiano, utilizando suas experiências, linguagens, vivências e seus conhecimentos (BOAVIDA et al., 2008). A pesquisa de Altoé (2017), de modo singular, mostrou essa possibilidade quando investigou as contribuições de atividades pautadas na elaboração de problemas para o ensino de conceitos de multiplicação e divisão em uma turma do $5^{\circ}$ ano do Ensino Fundamental de uma escola estadual.

Altoé (2017) revelou que a elaboração de problemas no contexto das pesquisas em âmbito nacional é ainda algo "prematuro". O autor, em sua revisão de literatura, buscou por trabalhos no âmbito nacional e internacional e mostrou que a maior incidência desse tema está no contexto internacional. Foram selecionados dez trabalhos, dos quais somente três eram oriundos de 
pesquisas brasileiras envolvendo a elaboração e/ou formulação de problemas (GONTIJO, 2007; MEDEIROS e SANTOS, 2007; SANTIAGO, 2011).

Os trabalhos de âmbito nacional citados na revisão de literatura de Altoé (2017) são frutos de pesquisas acadêmicas; um deles se refere à uma pesquisa de Mestrado realizada com alunos do Ensino Fundamental (SANTIAGO, 2011). A pesquisa de Medeiros e Santos (2007), publicada na revista Zetetiké, investigou a formulação de problemas por estudantes de uma escola pública, com idades entre 13 e 16 anos. Por outro lado, o trabalho de Gontijo (2007) é fruto de uma pesquisa de Doutorado que apontou a formulação e a resolução de problemas como estratégias para desenvolver a criatividade em Matemática de estudantes do Ensino Médio de uma escola particular. Vale ressaltar que tais pesquisas abordaram a formulação de problemas associada à resolução de problemas, o que nos leva a compreender a elaboração e/ou a formulação de problemas como algo que não se pode dissociar da resolução de problemas no contexto da aprendizagem matemática.

É importante pontuar que a Base Nacional Comum Curricular — BNCC (BRASIL, 2017) menciona a elaboração de problemas em diversos objetivos de aprendizagem ao longo dos anos de escolarização. Muitas vezes essa proposta está vinculada ao termo resolver e elaborar problemas, que o documento assim explica:

[...] que se pretende não apenas a resolução do problema, mas também que os alunos reflitam e questionem o que ocorreria se algum dado do problema fosse alterado ou se alguma condição fosse acrescida ou retirada. Nessa perspectiva, pretende-se que os alunos também formulem problemas em outros contextos. (BRASIL, 2017, p. 233)

Nesse sentido, foi que propusemos o desenvolvimento da última etapa da metodologia de Ensino-Aprendizagem-Avaliação de Matemática através da RP, de forma que os estudantes tivessem a possibilidade também de elaborar problemas, inseridos em um contexto de resolução de problemas vivenciados por eles em etapas anteriores.

\section{Procedimentos Metodológicos}

A pesquisa, com abordagem qualitativa, relatada neste artigo configurou-se como pesquisa-ação, cujo objetivo foi investigar a aprendizagem matemática dos estudantes do $5^{0}$ ano do Ensino Fundamental através da elaboração de problemas, indo ao encontro das considerações de Barbier (1985) e Thiollent (2008), os quais ressaltam que o pesquisador desempenha um papel 
ativo na realidade dos fatos observados - neste caso, uma turma específica de estudantes em uma escola do campo.

A ação desenvolvida pelo professor pesquisador buscou promover ampla e constante interação entre os estudantes e a professora regente da turma, em um contexto de aprendizagem mútua, com uma investigação sistemática. Como os professores regente e pesquisador mediaram a elaboração dos problemas pelos estudantes, entendemos que o trabalho de investigação pode ser considerado uma pesquisa-ação, tendo em vista ser uma "atividade de compreensão e de explicação da práxis dos grupos sociais por eles mesmos, com ou sem especialistas em ciências humanas e sociais práticas, com o fito de melhorar essa práxis" (BARBIER, 1985, p. 156).

O processo de elaboração dos problemas ocorreu, conforme explicitado na introdução, após a resolução dos problemas. Entendemos, conforme Chica (2001), que trabalhar a resolução de problemas antes do processo de elaboração é oportuno, pois os estudantes precisam ter contato primeiro com diferentes tipos de problemas para resolver, antes de criar os seus próprios.

Chica (2001) ressalta ser importante os estudantes conhecerem modelos de problemas que possam servir como ponto de partida para criar os seus. Foi nessa perspectiva de trabalho que propusemos a elaboração de problemas com os estudantes do $5^{\circ}$ ano da Escola Municipal Comunitária Rural "Padre Fulgêncio do Menino Jesus", localizada no município de Colatina, região noroeste do estado do Espírito Santo. Cada problema gerador resolvido por eles nos meses anteriores esteve relacionado a temáticas e conteúdos previstos no Plano de Estudo da escola em questão, conforme Quadro 1.

Quadro 1: Proposta para Elaboração de Problemas

Elabore um problema, considerando o trabalho que desenvolvemos com a resolução de problemas até o momento. Apresentamos como sugestão os conteúdos/assuntos envolvidos nos problemas geradores relacionados abaixo:

Problema Gerador 1 - Fração (João fazendo compras no supermercado)

- Problema Gerador 2 - Medidas de Comprimento (Quantidade de metros de cerca para cercar 0 terreno)

- Problema Gerador 3 - Medidas Agrárias (Medição do terreno dos amigos João, José e Joaquim)

Problema Gerador 4 - Medidas de Massa (Peso das sacas de café do Senhor Alfredo)

Problema Gerador 5 - Raciocínio Lógico (Distribuição de barracas dos agricultores na feira)

Problema Gerador 6 - Equivalência e Divisão (distribuição dos copos de suco entre as amigas Bárbara, Laura e Luana) 
Os estudantes estiveram livres para elaborar os problemas a partir de uma situação dada, segundo os três tipos de atividades, de acordo com o processo de elaboração de problemas proposto por Harpen e Sriraman (2013) apud Gontijo et al. (2019):

Livre - os alunos geram um problema a partir de uma situação dada, artificial ou naturalista; Semiestruturada - os alunos recebem uma situação aberta e são convidados a explorar a estrutura dessa situação por meio da aplicação de conhecimentos, habilidades, conceitos e relações a partir de suas experiências matemáticas anteriores; Estruturadas - a problematização baseia-se em um problema específico. (p. 68)

Os problemas elaborados pelos estudantes a partir da abordagem aqui exposta foram descritos e analisados na perspectiva metodológica da Análise Textual Discursiva (ATD), que, de acordo com as orientações de Moraes e Galiazzi (2016), envolve as etapas de unitarização, categorização e comunicação.

O processo de unitarização, também denominado pelos autores de "fragmentação de textos", emergiu dos textos dos problemas elaborados pelos estudantes, cabendo esclarecer que não nos propusemos a discutir, neste artigo, sua resolução e reescrita. Em seguida, construímos as categorias temáticas, que emergiram da fragmentação dos textos e, por fim, apresentamos a produção textual interpretativa dos problemas e dos dados - neste caso, os textos dos problemas elaborados pelos estudantes -, denominada por Moraes e Galiazzi (2016) de "metatexto", que combina "descrição e interpretação [e] que se constitui num esforço para expressar intuições e entendimentos atingidos a partir da impregnação intensa com o corpus da análise" (p. 59).

\section{Descrição e análise dos problemas elaborados pelos estudantes}

Nesta seção trazemos resultados detalhados do enredo textual dos problemas elaborados pelos estudantes a partir do contexto de resolução dos problemas geradores desenvolvidos anteriormente, conforme explicitado no Quadro 1. Seguimos as etapas do processo da ATD, de Moraes e Galiazzi (2016). Essas etapas consistem, inicialmente, na fragmentação dos textos dos problemas elaborados pelos estudantes, o processo de unitarização; em seguida, procuramos estabelecer as conexões e as relações entre as unidades de significados emergentes do processo de unitarização e introduzimos as categorias. Por fim, ao final desta seção, procuraremos expor a comunicação dos dados, alinhados aos nossos objetivos, ao analisar a forma como problemas elaborados pelos estudantes podem contribuir com a aprendizagem discente. 


\subsection{Fragmentando os textos}

O momento de fragmentação dos textos, a unitarização, de acordo com Moraes e Galiazzi (2016, p. 34), consiste na "desconstrução dos textos do corpus". Esse processo de desconstrução "implica examinar os textos em seus detalhes, fragmentando-os no sentido de produzir unidades constituintes, enunciados referentes aos fenômenos estudados" (MORAES e GALIAZZI, 2016, p. 33). No contexto de nosso trabalho, o corpus de pesquisa são os textos/enunciados dos problemas elaborados pelos estudantes.

Com o objetivo de melhor organizar as unidades de significado, utilizaremos as ideias de Vieira (2016), com adaptações. A sigla U.S. irá designar cada Unidade de Significado, seguida por algarismos indo-arábicos. Por exemplo, o código U.S.1 indica a primeira unidade de significado extraída dos textos mencionados.

As unidades de significado foram organizadas no Quadro 2. Inspirado no modelo organizacional de Vieira (2016), a primeira coluna representa o código da unidade de significado; a segunda coluna, os textos extraídos dos problemas elaborados; e, na terceira coluna, há as interpretações preliminares do professor pesquisador.

Quadro 2: Unidades de Significado dos problemas elaborados pelos estudantes

\begin{tabular}{|c|l|l|}
\hline U.S. & $\begin{array}{c}\text { Fragmentos de textos }{ }^{3} \text { dos problemas } \\
\text { elaborados pelos estudantes }\end{array}$ & Interpretação preliminar do Pesquisador \\
\hline 1 & "minha mãe vende marmitex" & $\begin{array}{l}\text { Elabora situações indiretamente relacionadas } \\
\text { ao contexto dos problemas geradores. }\end{array}$ \\
\hline 2 & $\begin{array}{l}\text { "vende marmitex por } \mathrm{R} \$ 10,00 " \\
\text { "vende } 20 \text { marmitex por dia" }\end{array}$ & $\begin{array}{l}\text { Estabelece relações com venda de produtos } \\
\text { envolvendo operações multiplicativas. }\end{array}$ \\
\hline 3 & "Maria Eduarda foi à feira" & $\begin{array}{l}\text { Elabora situações a partir do contexto dos } \\
\text { problemas geradores propostos. }\end{array}$ \\
\hline 4 & $\begin{array}{l}\text { "comprou } 2 \text { churrasquinhos que são } R \$ 2,50 \text { e } \\
\text { mais um refrigerante que é R\$ 4,00" }\end{array}$ & $\begin{array}{l}\text { Propõe situações com a compra de produtos } \\
\text { envolvendo operações aditivas com valores } \\
\text { monetários. }\end{array}$ \\
\hline 5 & $\begin{array}{l}\text { "na panha de café, minha mãe panhava cinco } \\
\text { saco de café por dia. Quantos sacos de café } \\
\text { ela panhava?" }\end{array}$ & $\begin{array}{l}\text { Elabora situações a partir do contexto dos } \\
\text { problemas geradores propostos, assim como } \\
\text { do contexto de vida, envolvendo operações } \\
\text { multiplicativas. }\end{array}$ \\
\hline
\end{tabular}

\footnotetext{
${ }^{3}$ Os fragmentos de textos são cópias literais dos problemas elaborados pelos estudantes participantes da pesquisa.
} 


\begin{tabular}{|c|c|c|}
\hline 6 & "Senhor Antônio colheu 80 sacas de café" & $\begin{array}{l}\text { Elabora situações a partir do contexto dos } \\
\text { problemas geradores propostos. }\end{array}$ \\
\hline 7 & $\begin{array}{l}\text { "o caminhão que ele contratou aguenta três } \\
\text { toneladas e meia" }\end{array}$ & $\begin{array}{l}\text { Elabora situações envolvendo medidas de } \\
\text { massa. }\end{array}$ \\
\hline 8 & $\begin{array}{l}\text { "o caminhão custa } 15.000 \text { mil e ele vai pagar } \\
\text { por } 5 \text { meses" }\end{array}$ & $\begin{array}{l}\text { Estabelece relações com a compra de } \\
\text { produtos envolvendo divisão. }\end{array}$ \\
\hline 9 & $\begin{array}{l}\text { "minha mãe vende chup-chup no sábado e no } \\
\text { domingo" }\end{array}$ & $\begin{array}{l}\text { Elabora situações indiretamente relacionadas } \\
\text { ao contexto dos problemas geradores. }\end{array}$ \\
\hline 10 & $\begin{array}{l}\text { "cada fim de semana vende } 80 \text { chup-chup" } \\
\text { "quantos irá arrecadar em um mês, sabendo } \\
\text { que custa } R \$ 1,00 \text { cada chup-chup" }\end{array}$ & $\begin{array}{l}\text { Elabora situações envolvendo pensamento } \\
\text { multiplicativo. }\end{array}$ \\
\hline 11 & $\begin{array}{l}\text { "meu pai panhou } 700 \text { sacas de café, cada saca } \\
\text { pesava } 60 \mathrm{~kg} \text { " }\end{array}$ & $\begin{array}{l}\text { Estabelece relação com o contexto dos } \\
\text { problemas geradores envolvendo unidades de } \\
\text { massa. }\end{array}$ \\
\hline 12 & "meu pai tem uma C-10 que cabe $7 \mathrm{t}$ " & $\begin{array}{l}\text { Estabelece relação com o contexto dos } \\
\text { problemas geradores envolvendo unidades de } \\
\text { massa. }\end{array}$ \\
\hline 13 & $\begin{array}{l}\text { "qual valor bruto irá receber pela venda do } \\
\text { café" }\end{array}$ & $\begin{array}{l}\text { Propõe situações envolvendo venda de } \\
\text { produtos a partir do contexto dos problemas } \\
\text { geradores. }\end{array}$ \\
\hline 14 & $\begin{array}{l}\text { "Luana convidou sua nova amiga para a festa } \\
\text { do pijama" }\end{array}$ & $\begin{array}{l}\text { Elabora situações externas (ou "desvinculadas } \\
\text { do") ao contexto dos problemas geradores. }\end{array}$ \\
\hline 15 & $\begin{array}{c}\text { "a mãe do João deu } \mathrm{R} \$ 18,00 \text { para comprar } \\
\text { produtos" }\end{array}$ & $\begin{array}{l}\text { Propõe situações envolvendo compra de } \\
\text { produtos com valores monetários. }\end{array}$ \\
\hline 16 & $\begin{array}{c}\text { "a mãe do João não sabia quantos reais ia } \\
\text { gastar e quantos ia sobrar, ajude a mãe do } \\
\text { João" }\end{array}$ & $\begin{array}{l}\text { Propõe situações envolvendo compra e venda } \\
\text { de produtos com valores monetários. }\end{array}$ \\
\hline 17 & $\begin{array}{l}\text { "a carreta que o Senhor Alfredo contratou } \\
\text { aguenta } 24 \mathrm{t} \text { " }\end{array}$ & $\begin{array}{l}\text { Estabelece relação com o contexto dos } \\
\text { problemas geradores envolvendo unidades de } \\
\text { massa. }\end{array}$ \\
\hline 18 & "Gabriel montou uma barraca de maçãs" & $\begin{array}{l}\text { Estabelece relação com o contexto dos } \\
\text { problemas geradores propostos. }\end{array}$ \\
\hline 19 & $\begin{array}{l}\text { "Barbara da barraca } 19 \text { tinha o sêxtuplo de } \\
\text { maçãs" }\end{array}$ & $\begin{array}{l}\text { Propõe situações envolvendo aumento } \\
\text { proporcional de quantidades. }\end{array}$ \\
\hline 20 & $\begin{array}{l}\text { "Rômulo, Luiz e Tiago são muito amigos e } \\
\text { estavam cansados de jogar videogame, foram } \\
\text { para o parque" }\end{array}$ & $\begin{array}{l}\text { Elabora situações indiretamente ao contexto } \\
\text { dos problemas geradores. }\end{array}$ \\
\hline
\end{tabular}




\begin{tabular}{|c|l|l|}
\hline 21 & $\begin{array}{l}\text { "no total foram } 12 \text { petecas, } 12 \text { carrinhos, } 60 \\
\text { bolinhas de gude e } 3 \text { bolas. Quantos } \\
\text { brinquedos cada criança ficou?" }\end{array}$ & $\begin{array}{l}\text { Propõe situações envolvendo adição e } \\
\text { divisão. }\end{array}$ \\
\hline 22 & "gastou 1/4 com maquiagem" & $\begin{array}{l}\text { Propõe situações envolvendo fração e } \\
\text { estabelecendo relação com o contexto dos } \\
\text { problemas geradores. }\end{array}$ \\
\hline 23 & "do que sobrou gastou metade com lanche" & $\begin{array}{l}\text { Propõe situações envolvendo divisão e } \\
\text { decrescimento proporcional. }\end{array}$ \\
\hline 24 & $\begin{array}{l}\text { "João estava fazendo compras" } \\
\text { "tinha que comprar arros e feijão" }\end{array}$ & $\begin{array}{l}\text { Elabora situações diretamente relacionadas } \\
\text { ao contexto dos problemas geradores. }\end{array}$ \\
\hline 25 & $\begin{array}{l}\text { "o feijão custava 4 R\$ e o arros custava 20" } \\
\text { "Ele tinha 100 reais comto que sobrou" }\end{array}$ & $\begin{array}{l}\text { Elabora relações com a compra de produtos } \\
\text { envolvendo adição e subtração }\end{array}$ \\
\hline 26 & "recebeu de troco 5,00 reais" & $\begin{array}{l}\text { Propõe situações envolvendo valores } \\
\text { monetários. }\end{array}$ \\
\hline 27 & "em sua mansão 3/6 de camas está ocupado" & $\begin{array}{l}\text { Propõe situações envolvendo fração, } \\
\text { estabelecendo relação com o contexto dos } \\
\text { problemas geradores. }\end{array}$ \\
\hline
\end{tabular}

Fonte: Acervo da Pesquisa

Direcionando 0 olhar para 0 Quadro 2, identificamos 27 unidades de significado relacionadas aos textos dos problemas elaborados pelos estudantes. Percebemos semelhanças com o contexto e com a temática dos problemas geradores realizados pelos estudantes antes dessa atividade. A maior parte das unidades - 5, 6, 7, 8, 11, 12, 13, 17 - envolveu situações relacionadas ao contexto do Problema Gerador 4 (Figura 1), com situações de compra, venda e medidas de café.

Alguns estudantes exploraram bastante o contexto e a temática dos problemas geradores listados no Quadro 1. É curioso destacar a elaboração do texto de um estudante que só trocou os dados numéricos, mantendo contexto e descrição do problema envolvendo a produção de café, conforme presenciamos na Figura 1.

Além de situações pertinentes ao contexto do Problema Gerador 4, identificamos outras unidades - $3,4,15,16,18,19,22,23$ - relativas ao contexto dos problemas geradores citados no Quadro 1. Uma quantidade menor de unidades - 1, 2, 9, 14, 20, 21 - envolveu outros contextos e temáticas. De fato, não raro, as experiências dos estudantes em momentos anteriores podem ajudar na escolha de métodos, procedimentos e condicionantes do problema em atividades de elaboração (GONTIJO, 2007). 


\section{Problema Gerador 4}

No final da colheita de caté o Senhor Alfredo conseguiu colher 55 sacas de café de $60 \mathrm{~kg}$ cada saca e precisa guardar o café no Armazém da Cooabriel em São Gabriel da Palha. Alfredo alugou um caminhão que suporta até 3 toneladas de peso e nẫo sabe se poderá transportar todo o café que produziu de uma só vez. Alfredo sem saber o que fazer foi até a Escola Padre Fulgêncio e pediu ajuda aos estudantes do $5^{\circ}$ Ano para ajudá-lo a descobrir se o café poderá ser transportado em uma única viagem, para nẫo pagar muito trete. E agora? Como podemos ajudar o Senhor Alfredo?

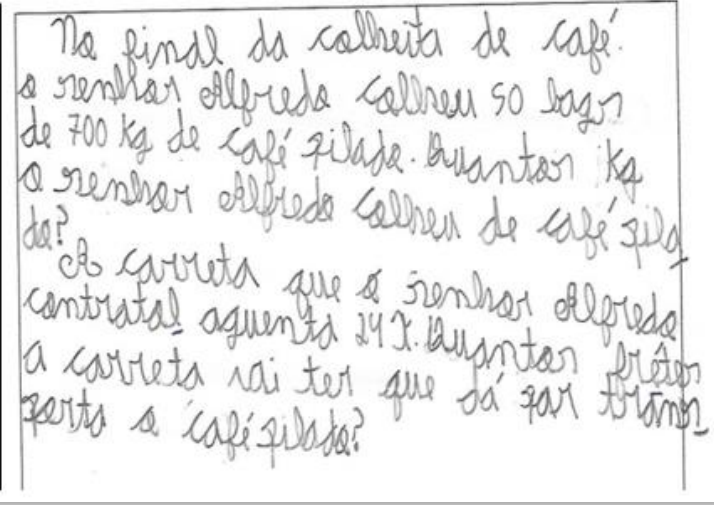

Figura 1: Problema elaborado por estudante envolvendo o problema das sacas de café (Acervo da Pesquisa)

Observando os textos dos problemas elaborados pelos estudantes, percebemos que quase a totalidade deles, mesmo os que não se relacionaram ao contexto dos problemas geradores, envolveu enredo com situações de compra e venda de produtos com valores monetários. Essa situação pode estar ligada aos interesses e aos desejos pessoais dos estudantes, sejam eles quais forem, e pode levá-los a interessar-se pela resolução do problema (CHICA, 2001).

Quase todos os problemas relacionados ao contexto de produção do café também envolveram situações de compra e venda com valores monetários. Somente quatro problemas, no geral, não geraram textos relacionados ao contexto de compra e/ou venda de produtos $A$ eles estão relacionadas as unidades de significado 7, 11, 12, 17, 20 e 21.

No contexto de elaboração dos textos dos problemas envolvendo a produção de café, não foi comum a exploração de unidade de medidas com toneladas, tendo em vista que somente dois problemas as utilizaram como eixo central. Talvez os estudantes não tivessem se sentido confortáveis e seguros em explorar tal conteúdo matemático naquela situação, já que a grande maioria explorou valores monetários relacionados a compra e venda de café.

É importante considerar que os textos dos problemas podem abarcar situações e interesses pessoais dos estudantes, mesmo não estando ligados diretamente ao contexto dos problemas geradores, como foi o caso do problema elaborado por um(a) estudante, que envolveu o nome dos colegas da sala em uma atividade no parque. Na Figura 2 apresentamos esse problema que empregou o raciocínio da adição e da divisão de brinquedos entre os colegas. 


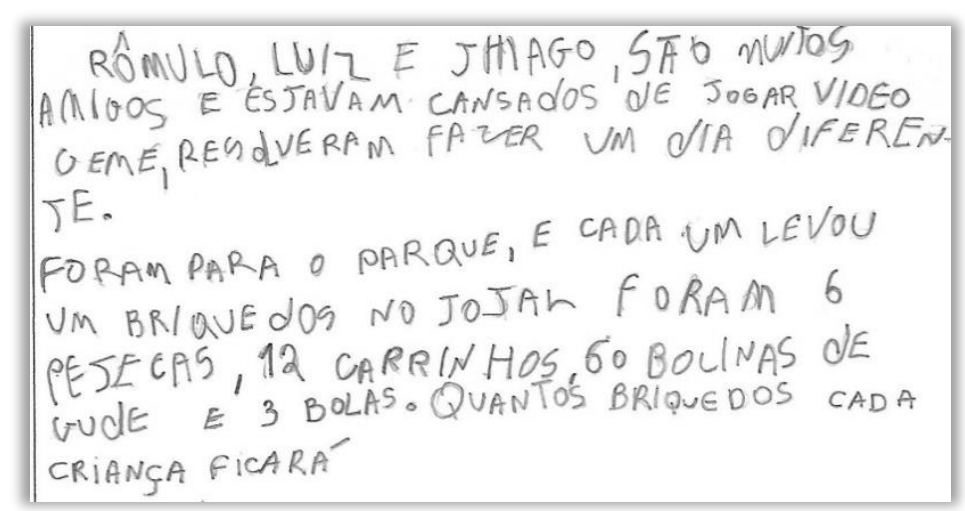

Figura 2: Problema elaborado por estudante, indiretamente relacionado ao contexto dos problemas geradores (Acervo da Pesquisa)

A elaboração de problemas pelos estudantes indiretamente relacionados às temáticas e ao contexto dos problemas geradores também se configura como possibilidade de aprendizagem, pois Ihes dá segurança e oportuniza mostrar outros interesses e vontades. 0 ambiente de liberdade e criatividade para a elaboração dos problemas possui potencial educativo e pode tornarse um recurso pedagógico nas aulas de Matemática (CHICA, 2001).

\subsection{Construindo as subcategorias e categorias de análise}

Nesta seção, apresentamos as categorias de análise que emergiram da fragmentação dos textos. Nesta etapa, agrupamos as unidades de significado de acordo com as características comuns entre elas, em um processo subjetivo de categorização dos dados.

Este processo consiste no agrupamento de elementos de significação próxima, que podem ser reunidos em diferentes níveis de categorias. Elas "constituem os elementos de organização do metatexto que se pretende escrever. É a partir delas que se produzirão as descrições e interpretações que comporão o exercício de expressar as novas compreensões [...]" (MORAES e GALIAZZI, 2016, p. 45).

Ao observarmos as unidades de significado extraídas dos textos dos problemas elaborados pelos estudantes, percebemos semelhanças no seu enredo, todos bastante direcionados a valores monetários envolvendo compra e venda de produtos e gêneros alimentícios, incluindo ou não situações que abordaram a temática dos problemas geradores.

O processo de categorização exige atenção, dedicação e retomada do objetivo da pesquisa - em nosso caso, o processo de aprendizagem discente pela elaboração de problemas matemáticos. Tal dedicação e cuidado contribuirão para a construção da última etapa do processo 
da ATD, denominado por Moraes e Galiazzi (2016) de "comunicação — metatexto". No Quadro 3 expomos a categorização originada da unitarização dos textos.

Quadro 3: Organização das subcategorias e categorias de análise dos textos dos problemas elaborados pelos estudantes

\begin{tabular}{|c|c|c|c|}
\hline $\begin{array}{l}\text { Unidades de } \\
\text { Significado }\end{array}$ & Aspectos em comum & Subcategorias & $\begin{array}{l}\text { Categorias } \\
\text { de Análise }\end{array}$ \\
\hline $4,21,25$ & $\begin{array}{c}\text { Apresentam } \\
\text { procedimentos/enredos com } \\
\text { valores monetários. }\end{array}$ & $\begin{array}{l}\text { Enredo/pensamento } \\
\text { envolvendo adição e } \\
\text { subtração }\end{array}$ & \multirow{7}{*}{$\begin{array}{l}\text { Aspectos } \\
\text { relacionados ao } \\
\text { enredo textual } \\
\text { envolvendo } \\
\text { conteúdos } \\
\text { matemáticos }\end{array}$} \\
\hline 2,10 & $\begin{array}{l}\text { Apresentam } \\
\text { procedimentos/enredos com } \\
\text { valores monetários. }\end{array}$ & \multirow{2}{*}{$\begin{array}{c}\text { Enredo/pensamento } \\
\text { envolvendo multiplicação e } \\
\text { divisão }\end{array}$} & \\
\hline $5,8,11,21$ & $\begin{array}{c}\text { Apresentam } \\
\text { procedimentos/enredos fora do } \\
\text { contexto monetário. }\end{array}$ & & \\
\hline $7,12,17$ & $\begin{array}{l}\text { Utilizam a medida de tonelada } \\
\text { como elemento central do } \\
\text { enredo textual do problema. }\end{array}$ & $\begin{array}{l}\text { Enredo/pensamento } \\
\text { envolvendo medidas de } \\
\text { massa }\end{array}$ & \\
\hline 19 & $\begin{array}{l}\text { Utiliza o aumento proporcional } \\
\text { como elemento central do } \\
\text { enredo do problema. }\end{array}$ & \multirow{3}{*}{$\begin{array}{l}\text { Enredo/pensamento } \\
\text { envolvendo fração, } \\
\text { diminuição/aumento } \\
\text { proporcional }\end{array}$} & \\
\hline 23 & $\begin{array}{l}\text { Utiliza a diminuição proporcional } \\
\text { como elemento central do } \\
\text { enredo do problema. }\end{array}$ & & \\
\hline 22,27 & $\begin{array}{l}\text { Utilizam a fração como } \\
\text { elemento central do enredo do } \\
\text { problema. }\end{array}$ & & \\
\hline $5,6,11$ & $\begin{array}{l}\text { Apresentam enredo textual } \\
\text { envolvendo a produção e a } \\
\text { colheita de café. }\end{array}$ & \multirow{2}{*}{$\begin{array}{l}\text { Procedimentos e ideias } \\
\text { envolvendo a temática do } \\
\text { Problema Gerador } 4\end{array}$} & \multirow{2}{*}{$\begin{array}{l}\text { Aspectos } \\
\text { relacionados } \\
\text { diretamente ao } \\
\text { contexto/temática } \\
\text { dos problemas } \\
\text { geradores }\end{array}$} \\
\hline 13 & $\begin{array}{l}\text { Apresenta enredo textual } \\
\text { envolvendo a venda de café. }\end{array}$ & & \\
\hline $\begin{array}{c}3,15,16,24 \\
26\end{array}$ & $\begin{array}{l}\text { Apresentam enredo textual } \\
\text { envolvendo compra e venda de } \\
\text { produtos diversos com valores } \\
\text { monetários. }\end{array}$ & \multirow{2}{*}{$\begin{array}{c}\text { Procedimentos e ideias } \\
\text { envolvendo a temática dos } \\
\text { problemas geradores } 1,5 \text { e } 6\end{array}$} & \multirow{2}{*}{$\begin{array}{l}\text { Aspectos } \\
\text { relacionados } \\
\text { diretamente ao } \\
\text { contexto/temática } \\
\text { dos problemas } \\
\text { geradores }\end{array}$} \\
\hline 18 & $\begin{array}{l}\text { Apresenta enredo textual } \\
\text { envolvendo frutas. }\end{array}$ & & \\
\hline
\end{tabular}




\begin{tabular}{|c|c|c|c|}
\hline 14,20 & $\begin{array}{c}\text { Estabelecem relações com o } \\
\text { enredo textual de situações } \\
\text { vivenciadas entre os colegas da } \\
\text { sala de aula. }\end{array}$ & $\begin{array}{c}\text { Procedimentos e ideias } \\
\text { envolvendo outros contextos } \\
\text { não explorados diretamente } \\
\text { nos problemas geradores }\end{array}$ & $\begin{array}{c}\text { Aspectos } \\
\text { relacionados } \\
\text { indiretamente ao } \\
\text { contexto/temática } \\
\text { dos problemas } \\
\text { geradores }\end{array}$ \\
\hline 1,9 & $\begin{array}{c}\text { Estabelecem relações com o } \\
\text { enredo textual de situações } \\
\text { vivenciadas com os familiares. }\end{array}$ & & \\
\hline
\end{tabular}

Fonte: Acervo da Pesquisa

Ao observarmos o Quadro 3, destacamos que algumas unidades de significado se encaixaram em mais de uma Categoria de Análise, considerando que envolveram questões relacionadas à temática dos problemas, assim como aos conteúdos matemáticos.

As 27 unidades de significado relacionadas na primeira coluna do Quadro 3 foram agrupadas e categorizadas visando à identificação de aspectos em comum entre elas, expressos na segunda coluna. Na terceira coluna estão indicadas as subcategorias, que foram fundamentais para a construção das categorias de análise, apresentadas na última coluna do quadro.

Na próxima seção, efetivamos a terceira e última etapa do processo de análise dos problemas elaborados pelos estudantes, denominada por Moraes e Galiazzi (2016) de "comunicação ou metatexto", apresentando análises e sínteses dos dados oriundos das categorias de análise.

\subsection{Comunicação dos dados}

Em se tratando da primeira categoria, relacionada a conteúdos matemáticos, identificamos 15 unidades de significado - 2, 4, 5, 7, 8, 10, 11, 12, 17, 19, 21, 22, 23, 25, 27 -, envolvendo as operações fundamentais de adição, subtração, multiplicação e divisão, assim como medidas de massa, fração e diminuição/aumento proporcional.

A maior parte das unidades de significado agrupadas nesta primeira categoria envolveram aspectos do problema gerador relacionado à produção de café. As unidades 5, 7, 8, 11, 12 e 17 exploraram esse contexto. Algumas delas, ligadas diretamente ao enredo textual do problema, empregaram unidade de medidas com tonelada; as outras exploraram o contexto de produção do café utilizando pensamento aditivo e multiplicativo, assim como aspectos monetários.

É possível também identificar, nos textos elaborados pelos estudantes, uma proximidade com o contexto pessoal de vida deles, assim como o interesse por questões vivenciadas no dia a 
dia. Selecionamos e expomos na Figura 3 fragmentos dos textos em que isso pode ser observado.

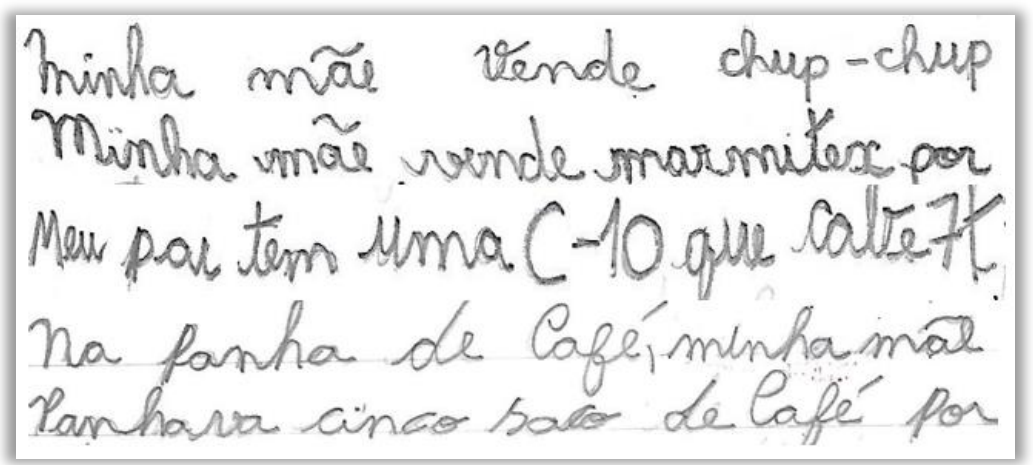

Figura 3: Fragmentos de textos dos problemas envolvendo interesse pessoal e contexto de vida dos estudantes (Acervo da Pesquisa)

A proximidade com o contexto de vida e o interesse pessoal dos estudantes pode tornarse um elemento favorável para a elaboração e a resolução de problemas, pois os estudantes acabam se interessando mais por eles, por entenderem que os problemas são "seus". Nos exemplos apresentados na Figura 3 percebemos o contexto familiar e a vida dos estudantes muito presentes nos problemas elaborados, tendo em vista que os quatro fragmentos exploraram a relação paterno-filial no enredo. Chica (2001) destaca que essa proximidade faz sentido e tem utilidade para eles, pois pode despertar o interesse para que se tornem leitores e escritores em Matemática.

Em relação aos aspectos conceituais e procedimentais, a maior parte dos textos explorou as operações fundamentais da Matemática, principalmente a multiplicação e a adição, com estruturas matemáticas mais simples, ou seja, com pequenas quantidades numéricas. As unidades de significado $2,4,5,8,10,11,20,21$ e 25 evidenciaram tais operações e envolveram, ainda, quantidades numéricas pequenas, conforme exemplificamos na Figura 4.

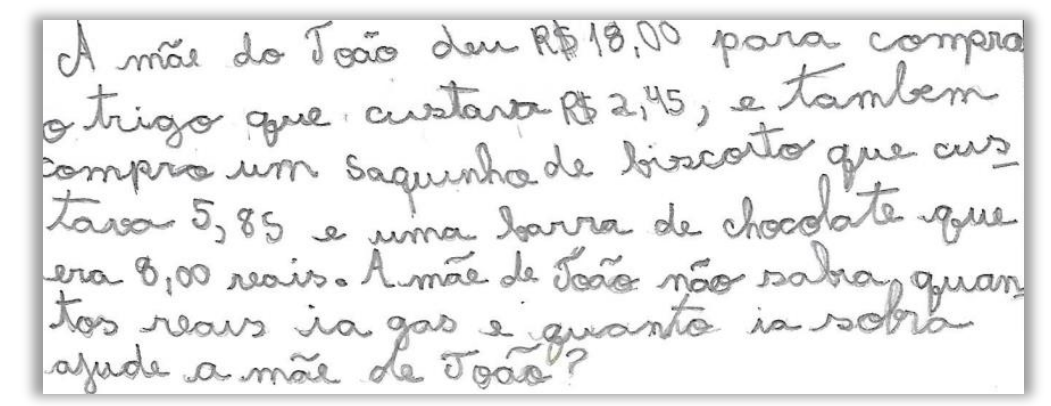

Figura 4: Problema envolvendo adição e subtração com números racionais em sua representação decimal (Acervo da Pesquisa)

O autor do problema apresentado na Figura 4 utilizou o mesmo personagem "João" do Problema Gerador 1, em um contexto de compra de produtos envolvendo valores monetários. É 
interessante perceber que o estudante utilizou números racionais em sua representação decimal, o que não foi explorado nos problemas geradores. Em um contexto de ajudar outra pessoa, mais uma vez se faz presente uma relação paterno-filial. Os valores monetários empregando números racionais com representação decimal podem expressar situações reais vivenciadas pelo estudante. A abordagem de outras estruturas matemáticas e de conteúdos não explorados mostra segurança e criatividade em atividades de elaboração de problemas (PELCZER, 2008 apud GONTIJO et al., 2019).

Outro exemplo que podemos associar à criatividade e à segurança na exploração de "novos" conteúdos e estruturas matemáticas esteve relacionado ao aumento proporcional de quantidades. Nesse caso, a estrutura matemática do problema elaborado foi diferente, porém, 0 contexto temático envolveu indiretamente aspectos explorados no problema gerador 5 . A Figura 5 mostra essa exploração com aumento proporcional.

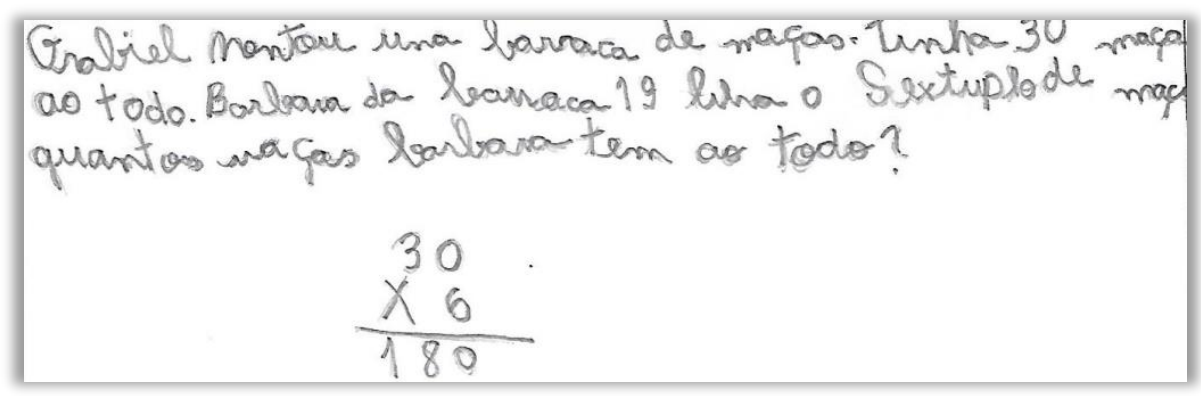

Figura 5: Problema envolvendo aumento proporcional (Acervo da Pesquisa)

Apesar de não termos solicitado aos estudantes que também resolvessem os problemas, 0 autor do problema apresentado na Figura 5 fez questão de resolvê-lo, o que pode mostrar segurança, autonomia e confiança na elaboração e na resolução do problema, tendo em vista que os estudantes não estão acostumados a elaborá-los. É importante considerar que os estudantes mencionaram que ainda não tinham tido a oportunidade de fazer uma atividade como essa, de inventar problemas.

Essa afirmação dos estudantes vai ao encontro das considerações de Gontijo et al. (2019, p. 70), ao destacar que "infelizmente, contudo, o trabalho com elaboração de problemas aparenta não ter ganhado ainda a devida importância nos espaços escolares".

Chica (2001) ressalta que o estudante, ao ter a oportunidade de criar seus próprios problemas, precisa organizar o que sabe, dando estrutura e sentido adequados ao texto, para que possa comunicar o que pretende. Ao apresentar a resposta do problema, conforme a Figura 5 , 
mesmo não sendo solicitada a resolução, o estudante mostrou controle sobre o texto e domínio das ideias matemáticas nele envolvidas.

Nas atividades de elaboração dos problemas é comum, também, identificarmos um pouco de insegurança e estranhamento inicial por parte dos estudantes, pois estão em um ambiente livre para criar situações e problemas. Alguns demoraram um pouco para iniciar o processo da escrita, pois esperavam por algum comando por parte dos professores pesquisador e regente. Essa insegurança e esse estranhamento talvez tenham se refletido na própria escrita e no enredo textual dos problemas elaborados.

Ainda em relação à primeira categoria temática, envolvendo aspectos de conteúdos matemáticos, identificamos alguns textos com escassez de dados numéricos e falta de estrutura textual. Entendemos que a insegurança, o estranhamento inicial e, até, a inexperiência para a elaboração de problemas possam ter contribuído para essa escassez. Escolhemos um problema para representar a falta de dados numéricos e textuais, exposto na Figura 6.

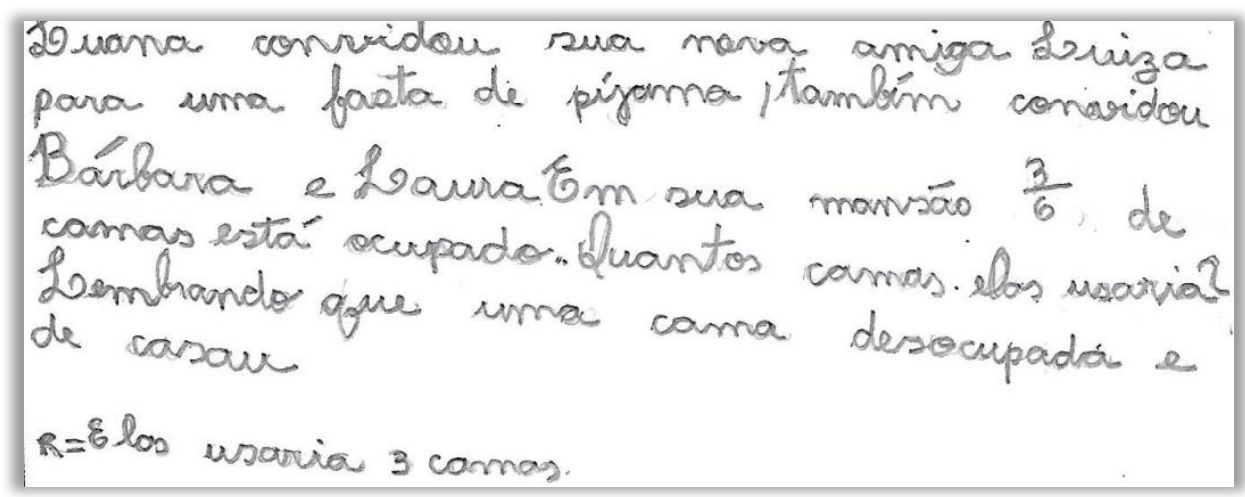

Figura 6: Problema envolvendo escassez de dados (Acervo da Pesquisa)

Ao analisarmos esse problema, consideramos que ele precisa de modificações para tornar-se mais compreensível; faltam dados numéricos, como, por exemplo, a quantidade de camas existente na casa. Entendemos que a autora do problema, ao apresentar a informação de que uma cama é de casal, supôs que pudessem dormir duas amigas nessa cama e as outras duas em camas de solteiro, totalizando três camas, conforme apresentou na resposta.

Problemas como este podem ser uma boa oportunidade para estimular a capacidade crítica dos estudantes para perceberem a falta de dados e informações. Chica (2001) ressalta ser importante e necessário estimular a capacidade crítica e questionadora dos estudantes, levantando hipóteses, comunicando ideias e não desprezando problemas dessa natureza.

Em relação à segunda categoria de análise - Aspectos relacionados diretamente ao 
contexto/temática dos problemas geradores - identificamos dez unidades de significado - 3, 5, $6,11,13,15,16,18,14,26$ - , sendo que o enredo da maior parte delas envolve produção, compra e venda de café, em conexão com o Problema Gerador 4. Identificamos, ainda, outros problemas que exploraram compra e venda de produtos em supermercados e/ou feiras. Alguns deles já foram apresentados na primeira categoria, já que envolveram conteúdos matemáticos associados às temáticas dos problemas geradores.

Destacamos nesta categoria a predominância de situações envolvendo compras e vendas de produtos e/ou gêneros alimentícios em diversas circunstâncias do cotidiano dos estudantes. A linguagem do seu convívio diário com outras pessoas e a importância de determinados objetos configuram-se como fatores importantes na elaboração de problemas, que podem ser explorados pelos professores, tornando-se recursos interessantes para os estudantes (YEVDOKIMOV, 2005).

A terceira categoria temática envolveu Aspectos relacionados indiretamente ao contexto/temática dos problemas geradores, com quatro unidades de significado - 1, 9, 14, 20. Embora ainda ligada ao contexto de compra e venda de produtos com valores monetários, expressa situações imaginárias vivenciadas entre colegas e familiares. Consideramos pertinente a emersão desta categoria de análise, porque ela evidencia a criatividade dos estudantes ao elaborar textos em contextos diferentes dos problemas geradores, mesmo constituídos de um número pequeno de unidades de significado.

Para uma melhor e mais conclusiva representação dos textos elaborados pelos estudantes em relação aos conteúdos matemáticos e aos contextos temáticos dos problemas, apresentamos, no Gráfico 1, o quantitativo dos problemas em relação a tais conteúdos e temáticas.

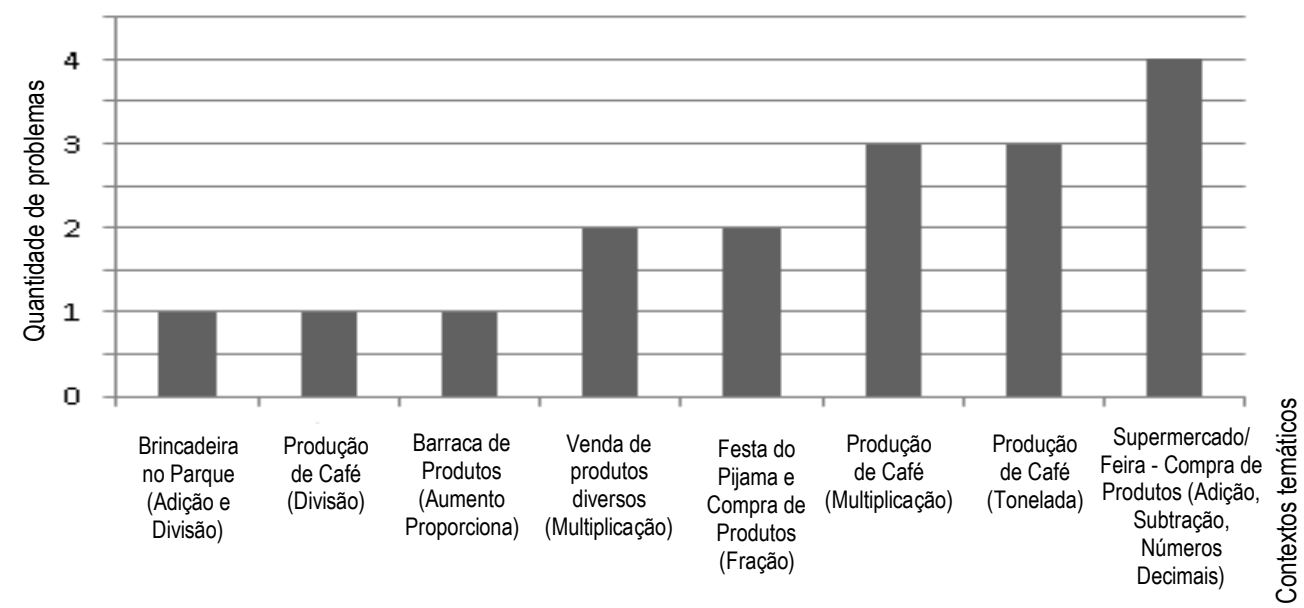

Gráfico 1: Representação gráfico-quantitativa dos problemas elaborados pelos estudantes (Elaboração dos Autores)

Em linhas gerais, podemos inferir, a partir do Quadro 3, que a maior parte dos textos dos 
problemas elaborados pelos estudantes esteve relacionada ao contexto de compras de produtos no supermercado ou na feira, envolvendo as operações fundamentais da multiplicação e da adição. Em número um pouco menor estão os textos envolvendo a produção de café, explorada no quarto problema gerador. Em menor quantidade, textos com a exploração de outros contextos e conteúdos matemáticos, como é o caso de grandezas proporcionais e números racionais na representação decimal, que foram também importantes na atividade de elaboração dos problemas, considerando os critérios de criatividade, autonomia e originalidade.

\section{Considerações}

Inicialmente, é relevante considerar que o foco central do trabalho desenvolvido neste artigo foi a elaboração de problemas, ou seja, os textos elaborados pelos estudantes, configurando novos problemas, conforme sugerido na décima etapa da metodologia de Ensino-AprendizagemAvaliação de Matemática através da RP (ALLEVATO e ONUCHIC, 2014). 0 aprimoramento, a reescrita e a resolução dos problemas não foram explorados diretamente nesta parte da pesquisa.

A elaboração de problemas configura-se como uma etapa importante e integrante da metodologia de Resolução de Problemas, tendo em vista que o processo de produção da escrita matemática pode ser um aspecto para ótimas discussões em sala de aula, podendo ocorrer durante ou depois da elaboração dos problemas (CHICA, 2001).

Nesse entendimento de que a elaboração de problemas pode ser considerada como parte da proposição de novos problemas, etapa importante da metodologia de Ensino-AprendizagemAvaliação de Matemática através da RP, é que propusemos analisar a contribuição de problemas elaborados por estudantes para a aprendizagem discente em uma Escola Comunitária Rural.

Em consonância com o objetivo assim especificado, o processo de elaboração dos problemas pelos estudantes ocorreu em um ambiente de liberdade e tranquilidade para construírem a proposta que quisessem, tendo em vista a oportunidade de resolver os problemas geradores nas etapas anteriores da metodologia de Ensino-Aprendizagem-Avaliação de Matemática através da RP. A liberdade para mover-se livremente entre temas e a expressão por preferências pessoais na elaboração de problemas influenciam na experiência emocional de complementá-los e no desejo de envolver-se em tarefas semelhantes (GONTIJO et al., 2019).

Nesse ambiente de liberdade, inferimos que nos textos elaborados os estudantes 
mostraram certa autonomia, segurança e criatividade, quando relacionaram o enredo textual do problema com outros conteúdos matemáticos não explorados nos problemas geradores, como é o caso da utilização de números racionais na representação decimal e das grandezas proporcionais.

Ainda em relação aos conteúdos matemáticos, percebemos que os textos elaborados pelos estudantes envolveram, em sua maioria, as operações fundamentais da Matemática, principalmente a adição e a multiplicação, conforme mencionamos na seção de comunicação dos dados. Entendemos que esse envolvimento e essa abordagem com as operações fundamentais se referem à opção por uma situação que traga mais segurança aos estudantes. Insistindo neste tipo de trabalho, podemos estimulá-los a serem mais ousados e avançar mais nestes aspectos.

De certa forma, eles estiveram seguros, empenhados e motivados durante a elaboração dos problemas, o que proporcionou a produção de estruturas textuais matemáticas com mais sentido e significado para eles. Na aprendizagem matemática com a perspectiva da Elaboração de Problemas, a motivação pode ser considerada como um ponto de partida na promoção do interesse e do envolvimento dos estudantes nas atividades escolares.

Kilpatrick (1987) destaca, em sua pesquisa, a importância do trabalho com a formulação de problemas para promover pensamentos criativos e flexíveis em contextos de aprendizagem diferentes do habitual, principalmente com crianças em etapas iniciais de escolarização. 0 autor acredita no potencial da formulação de problemas como um recurso na aprendizagem matemática discente.

O protagonismo, a autonomia e a motivação dos estudantes no desenvolvimento das atividades em uma escola com a metodologia de trabalho da Pedagogia da Alternância são elementos muito presentes, com possibilidades de associar a aprendizagem matemática através da elaboração e da resolução de problemas. A presente pesquisa mostrou que a motivação, a liberdade e a autonomia foram importantes para o envolvimento dos estudantes com a elaboração dos problemas.

Concluímos que a aprendizagem dos estudantes se consolidou ainda mais em relação às operações fundamentais da Matemática, pois não identificamos escassez de dados nos textos dos problemas envolvendo tais operações. Tais textos, de certa forma, mostraram pouca liberdade para pensar contextos diferentes dos problemas geradores, porém a elaboração de problemas apresenta-se como uma possibilidade para desenvolver aspectos da criatividade e da criticidade 
dos estudantes, pois os alunos abordaram outros contextos temáticos e outros conteúdos matemáticos. Conforme já explicitamos, entendemos que a persistência neste tipo de atividades com os alunos pode auxiliá-los a avançar nesse desenvolvimento.

Portanto, o trabalho com a elaboração de problemas pode tornar-se mais um recurso em favor da aprendizagem matemática, tão importante quanto a resolução de problemas e outras metodologias, principalmente em relação aos aspectos de criatividade, autonomia, flexibilidade, comunicação e originalidade, o que mostra a necessidade de incentivar mais o trabalho docente com a elaboração de problemas, abrindo possibilidades, inclusive, para pesquisas futuras.

\section{Referências}

ALLEVATO, Norma Suely Gomes; ONUCHIC, Lourdes de la Rosa. Ensino-aprendizagemavaliação de Matemática: por que através da resolução de problemas. In: ONUCHIC, Lourdes de la Rosa; ALLEVATO, Norma Suely Gomes; NOGUTI, Fabiane Cristina Höpner; JUSTULIN, Andresa Maria. (Org.). Resolução de problemas: teoria e prática. Jundiaí: Paco Editorial, 2014, p. $35-52$.

ALTOÉ, Renan Oliveira. Formulação de problemas do campo conceitual multiplicativo no Ensino Fundamental: uma prática inserida na metodologia de resolução de problemas. 2017. 227f. Dissertação (Mestrado em Educação em Ciências e Matemática) — Instituto Federal de Educação, Ciências e Tecnologia do Espírito Santo. Vitória.

ANDRADE, Silvanio. Um caminhar crítico reflexivo sobre resolução, exploração e proposição de problemas matemáticos no cotidiano da sala de aula. In: ONUCHIC, Lourdes de la Rosa; LEAL JUNIOR, Luiz Carlos; PIRONEL, Marcio (Org.). Perspectivas para resolução de problemas. São Paulo: Livraria da Física, 2017, p. 355-395.

BARBIER, René. A pesquisa-ação na instituição educativa. Tradução de Estela dos Santos Abreu, com a colaboração de Maria Wanda Maul de Andrade. Rio de Janeiro: Zahar, 1985.

BOAVIDA, Ana Maria Roque; PAIVA, Ana Luisa; CEBOLA, Graça; VALE, Isabel; PIMENTEL, Teresa. A experiência matemática no Ensino Básico. Programa de Formação Contínua em Matemática para Professores dos $1 .{ }^{\circ}$ e $2 .{ }^{\circ}$ Ciclos do Ensino Básico. Lisboa: Direção-Geral da Educação, 2008.

BONOTTO, Cinzia. Artifacts as sources for problem-posing activities. Educational Studies in Mathematics, New York, n. 83, p. 37-55, oct. 2012.

BRASIL. Ministério da Educação. Secretaria de Educação Básica. Base Nacional Comum Curricular: Educação Infantil e Ensino Fundamental. Brasília: MEC/SEB, 2017.

CHICA, Cristiane Henriques. Por que formular problemas? In: SMOLE, Kátia Stocco; DINIZ, Maria Ignez. (Org.). Ler, escrever e resolver problemas: habilidades básicas para aprender Matemática. 1. ed. reimp. São Paulo: Artmed, 2001, p. 151-173. 
DANTE, Luís Roberto. Formulação e resolução de problemas de Matemática: teoria e prática. São Paulo: Ática, 2011.

GONTIJO, Cleyton Hércules; CARVALHO, Alexandre Tolentino de; FONSECA, Mateus Gianni; FARIAS, Mateus Pinheiro de. Criatividade em Matemática: conceitos, metodologias e avaliação. Brasilia: Editora UnB, 2019.

GONTIJO, Cleyton Hércules. Estratégias para o desenvolvimento da criatividade em Matemática. Linhas Críticas, Brasília, v. 12, n. 23, jul./dez. 2006.

GONTIJO, Cleyton Hércules. Relações entre criatividade, criatividade em Matemática e motivação em Matemática de alunos do Ensino Médio. 2007. 194f. Tese (Doutorado em Psicologia) Instituto de Psicologia. Universidade de Brasília. Brasília.

HOUAISS, Antônio; VILLAR, Mauro de Salles; FRANCO, Francisco Manoel de Mello. Dicionário Houaiss da Língua Portuguesa. Rio de Janeiro: Objetiva, 2001.

KILPATRICK, Jeremy. Problem formulating: where do good problems come from? In: SCHOENFELD, Alan H. (Ed.). Cognitive science and mathematics education. Hillsdale, New Jersey: Erlbaum, 1987, p. 123-147.

MEDEIROS, Kátia Maria; SANTOS, Antônio José Barboza. Uma experiência didáctica com a Formulação de Problemas matemáticos. Zetetiké, Campinas, v. 15, n. 28, jul./dez. 2007.

MORAES, Roque; GALIAZZI, Maria do Carmo. Análise textual discursiva. 3. ed. ljuí: Unijuí, 2016.

SANTIAGO, Ivana. Formulação e resolução de problemas matemáticos: um estudo exploratório sobre o pensamento de crianças do Ensino Fundamental. 2011. 121f. Dissertação (Mestrado em Educação) - Centro Universitário Moura Lacerda. Ribeirão Preto.

THIOLLENT, Michel. Metodologia da pesquisa-ação. 16. ed. São Paulo: Cortez, 2008.

VAN DE WALLE, John A. Matemática no Ensino Fundamental: formação de professores e aplicação em sala de aula. Tradução de Paulo Henrique Colonese. 6. ed. Porto Alegre: Artmed, 2009.

VIEIRA, Gilberto. Tarefas exploratório-investigativas e a construção de conhecimentos sobre figuras geométricas espaciais. 2016. 169f. Tese. (Doutorado em Ensino de Ciências e Matemática) - Universidade Cruzeiro do Sul. São Paulo.

YEVDOKIMOV, Oleksiy. On development of students' abilities in problem posing: a case of plane geometry. In: 4th MEDITERRANEAN CONFERENCE ON MATHEMATICS EDUCATION, 2005, Palermo. Proocedings of the $4^{\text {th }}$ MCME. Palermo, 2005, p. 255-267. 